\title{
Bacterial Ball as an Unusual Finding in Patients With Chronic Rhinosinusitis
}

\author{
Dong-Kyu Kim ${ }^{1, \star} \cdot$ Young Chan Wi ${ }^{2, \star} \cdot$ Su-Jin Shin ${ }^{2} \cdot$ Youn II Jang ${ }^{3} \cdot$ Kyung Rae Kim ${ }^{3} \cdot$ Seok Hyun Cho ${ }^{3}$ \\ ${ }^{I}$ Department of Otorhinolaryngology-Head and Neck Surgery, Chuncheon Sacred Heart Hospital and Nano-Bio Regenerative Medical Institute, \\ Hallym University College of Medicine, Chuncheon; '2Departments of Pathology and ${ }^{3}$ Otorhinolaryngology-Head and Neck Surgery, Hanyang \\ University College of Medicine, Seoul, Korea
}

Objectives. Pathophysiology of chronic rhinosinusitis (CRS) is very complex and has not yet been clearly understood. To date, various factors have been researched to have relations with the pathogenesis of CRS, such as superantigens and biofilms. Recently, we found an unusual pathological finding in patients with CRS, and we called this new entity as bacteria ball (or bioball). In this study, we analyze the clinical characteristics of bacteria ball occurred in CRS.

Methods. This study enrolled consecutive 247 patients with CRS who underwent functional endoscopic sinus surgery from January 2015 to August 2016. The diagnosis of bacterial ball was made when negative in Gomori-methenamine-silver stain and positive in Gram stain. Histologically, bacterial ball was defined as acellular mucous materials with bacterial colonies and inflammatory cell infiltrates. We compared clinical data and computed tomography (CT) findings between fungal and bacterial balls.

Results. Six cases (2.4\%) of CRS were confirmed histologically as bacterial ball. Most of them were found in the maxillary sinus of CRS without nasal polyposis (66.7\%). Bacterial ball was green or brown colored materials similar to fungal ball which was harder and tightly adherent to the antral mucosa. Compared to fungal ball, patients with bacterial ball showed significantly less peripheral eosinophils $(P=0.011)$ and calcification in CT scans $(P=0.003)$.

Conclusion. Bacterial ball is unusual findings occurred in patient with CRS which is different from fungal ball and biofilm. For diagnosis of bacterial ball, Gram stain is essentially required to identify bacterial colonies. Bacterial ball might appear to be evidence of a new strategy for living in the paranasal sinuses.

Keywords. Sinusitis; Fungi; Bacteria; Endoscopic Surgery

\section{INTRODUCTION}

Chronic rhinosinusitis (CRS) is a heterogeneous disease characterized by local inflammation of the upper airways and sinuses that persists for at least 12 weeks [1]. Epidemiologic studies de-

\footnotetext{
- Received March 25, 2017

Revised May 14, 2017

Accepted May 16, 2017

- Corresponding author: Seok Hyun Cho

Department of Otorhinolaryngology-Head and Neck Surgery, Hanyang

University College of Medicine, 222-1 Wangsimni-ro, Seongdong-gu,

Seoul 04763, Korea

Tel: +82-2-2290-8583, Fax: +82-2-2290-8588

E-mail: shcho@hanyang.ac.kr

*The first two authors contributed equally to this study.
}

scribed that CRS affects about $4 \%$ to $11 \%$ of general population [2-4], and is associated with substantial impaired quality of life $[3,5]$. Currently, it divided into two groups based on nasal endoscopic findings, either accompanied by nasal polyps (CRSwNP) or without nasal polyps (CRSsNP) [1]. Moreover, there are clinical subtypes of allergic fungal rhinosinusitis and several comorbid conditions such as asthma, aspirin intolerance, and cystic fibrosis. Despite the many hypotheses presented, the exact pathogenesis of CRS is still unknown [1].

Bacterial infection is one of the major causes of CRS and there have been changing and expanding spectrums of its pathogenic mechanisms including anaerobic infection, biofilm formation, secretion of superantigens and altered microbiome [6,7]. However, systemic review of studies on antibiotic therapy for

Copyright $\odot 2018$ by Korean Society of Otorhinolaryngology-Head and Neck Surgery.

This is an open-access article distributed under the terms of the Creative Commons Attribution Non-Commercial License (http://creativecommons.org/licenses/by-nc/4.0)

which permits unrestricted non-commercial use, distribution, and reproduction in any medium, provided the original work is properly cited. 
CRS showed lack of sufficient evidences supporting its efficacy [8-10]. All of the bacteria-related factors listed above may make antibiotic treatment difficult to achieve in CRS. These facts serve as barriers that cannot be easily proven despite the correct hypothesis. Moreover, we think that there are still many unknown factors for CRS and bacteria that have very different behaviors and survival strategies.

Recently we reported two cases of unusual findings occurred in the maxillary sinuses in patients with CRSsNP [11]. Suspected fungal balls were sent to the Department of Pathology but confirmed as bioball which was consisted of acellular matrix and multiple bacterial colonies. We though that sinus surgeons in the world often may be experienced similar cases. However, it would not have been reported because it was overlooked or difficult to explain. In this study, we performed a retrospective review to characterize bacterial ball (bioball) in patients with CRS.

\section{MATERIALS AND METHODS}

\section{Subjects}

From January 2015 to August 2016, we performed a retrospective review of clinical data and pathologic report of adult patients (aged $\geq 18$ years) with CRS who had undergone functional endoscopic sinus surgery (FESS). The diagnosis of CRS was based on history, physical examination, nasal endoscopy, and computed tomography (CT) findings of the sinuses according to the 2012 European position paper on rhinosinusitis and nasal polyps [1]. We excluded the following conditions: antrochoanal polyp $(n=2)$, organizing hematoma $(n=1)$, inverted papilloma $(n=5)$, and malignancy $(n=1)$, and finally enrolled a total of 247 patients with CRS. The study was approved by the Institutional Review Board of Hanyang University Medical Center (IRB No. 2016-12-008).

\section{Histological diagnosis of bacterial balls}

All specimens were formalin-fixed, paraffin-embedded, and stained with hematoxylin and eosin (H\&E) for pathological examination. Gomori-methenamine-silver (GMS) and Gram stain were also performed to determine fungal organisms and bacterial species. All pathologic materials were reviewed by two pa-

\section{H I G G H L I}

- We proposed a bacterial ball (or bioball) as an unusual finding or different phenotype in chronic rhinosinusitis.

- If the fungal ball-like materials do not accompany with calcification on computed tomography scans, we could suspect the presence of bacterial ball.

- Bacterial ball is defined as biomaterials containing bacterial colonies which can be stained with Gram stain. thologists (YCW, SJS). Bacteria ball was defined as acellular mucous materials with gram-positive/negative bacterial colonies and inflammatory cell infiltrates. Specimens with fungal organism, confirmed by GMS stain were considered as fungal ball or fungal infection.

\section{Clinical characterization of bacterial balls}

When histologically confirmed by bacteria ball, the surgical videos were reviewed and their gross characteristics were observed. And we obtained representative photos of bacteria ball. Bacteria ball is one of the unusual finings in CRS patients and is very similar to fungal ball. Thus it is difficult to distinguish it from each other. Therefore, we compared clinical data to find out any differences between them.

\section{Statistics}

Because of the relatively small sample size of sinonasal bacterial balls and non-normal distribution, continuous variables were presented as medians with interquartile range. Statistical significance $(P<0.05)$ was analyzed with the Mann-Whitney $U$-test, Pearson chi-square, and Fisher exact test. All statistical analyses were performed using IBM SPSS ver. 21.0 (IBM Corp., Armonk, NY, USA).

\section{RESULTS}

\section{Prevalence of sinonasal bacterial balls}

Among the total of 247 patients who underwent FESS, CRSsNP was 144 cases (58.3\%) and CRSwNP was 103 cases (41.7\%). Of these, 6 cases ( $2.4 \%$ of CRS) were confirmed histologically as bacterial ball. Bacterial ball occurred in 4 patients with CRSsNP (66.7\%) and 2 patients with CRSwNP (33.3\%). Clinical profiles of 6 patients with bacterial ball are summarized in Table 1 .

\section{CT findings of sinonasal bacteria balls}

The location of bacterial balls was maxillary sinus in 4 cases $(66.7 \%)$ and ethmoid sinus in 2 cases $(33.3 \%)$ (Table 1$)$. There were 5 cases $(83.3 \%)$ with no calcification, and 1 case $(16.7 \%)$ with accompanying calcification. All bacterial balls were unilateral and did not involve multiple sinuses (Fig. 1). In addition, 2 cases $(33.3 \%)$ showed bone remodeling with expansile growth.

\section{Operative findings of sinonasal bacteria balls}

After antrostomy, green or brown colored materials similar to fungal balls were found in the maxillary sinus with wet state (Fig. 2). The difference from the fungal ball was that it was harder and less easily broken, and tightly adherent to the maxillary sinus mucosa, making complete removal difficult. Therefore, removal of bacterial ball through the maxillary ostium occasionally resulted in residuals, so wide antrostomy or antral puncture was needed. 
Table 1. Profiles of six patients with sinonasal bacterial balls

\begin{tabular}{llccccc}
\hline Case & Sex & Age $(\mathrm{yr})$ & Preoperative diagnosis & Location of bioball & Calcification in CT scan & Bacterial colonies in Gram stain \\
\hline 1 & Female & 51 & CRSsNP & Maxillary & No & Yes \\
2 & Female & 57 & CRSsNP & Maxillary & No & Yes \\
3 & Male & 57 & CRSsNP & Maxillary & Yos & Yes \\
4 & Male & 63 & CRSsNP & Ethmoid & No & Yes \\
5 & Female & 34 & CRSwNP & Maxillary & No & Yes \\
6 & Male & 63 & CRSwNP & Ethmoid & \\
\hline
\end{tabular}

CT, computed tomography; CRSsNP, chronic rhinosinusitis without nasal polyps; CRSwNP, chronic rhinosinusitis with nasal polyps.
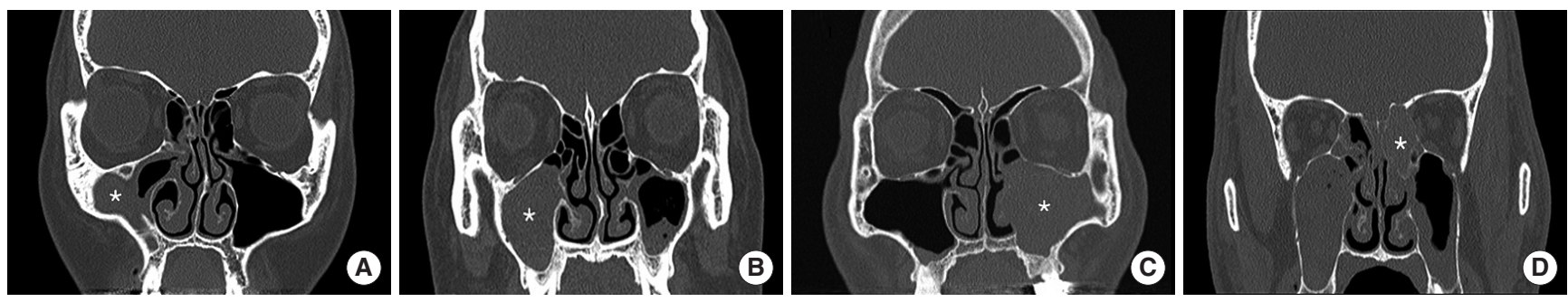

Fig. 1. Radiological findings for sinonasal bacterial balls. Soft tissue densities were found in the maxillary (A-C) and posterior ethmoid sinuses (D). They filled the involved sinuses partially $(A)$ or completely (B-D), and showed signs of expansile growth with bone remodeling (C, D). Each asterisk $\left(^{*}\right)$ indicates the location of bioball.
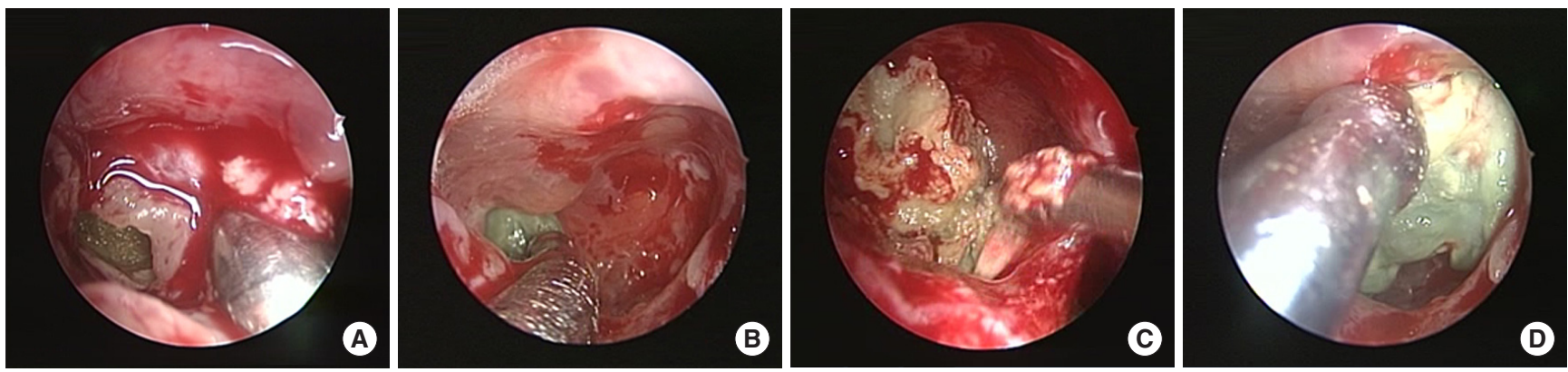

Fig. 2. Operative findings for maxillary bacterial balls. When performing maxillary antrostomy $(A, B)$, green colored bacterial balls were found in the maxillary sinus. They were gel-like or semisolid, and tightly attached to the sinus mucosa (C, D).
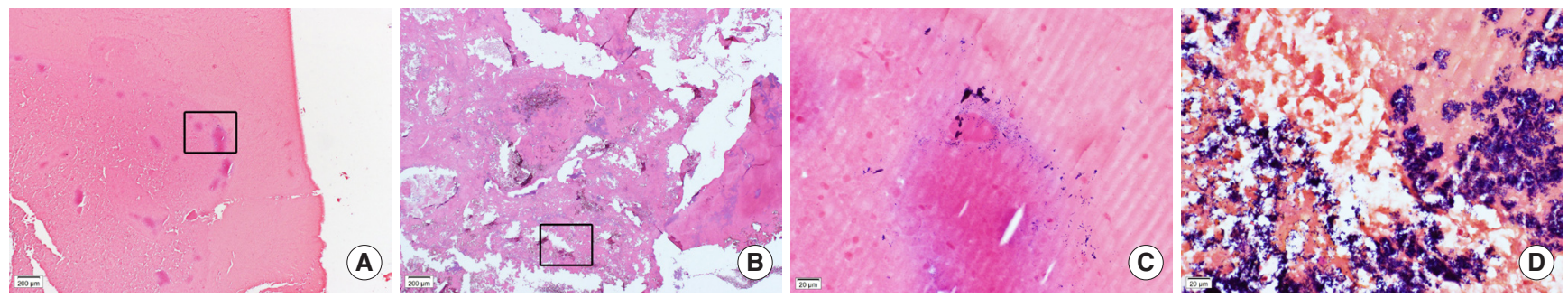

Fig. 3. Pathology findings for sinonasal bacterial balls. Bacterial balls consisted of matrix with thick acellular mucous material (A, B; H\&E stain, $\times 40)$ in which gram-positive bacteria colonies were found in central (C; box area of panel A, Gram stain, $\times 400)$ or peripheral $(D$; box area of panel B, Gram stain, $\times 400$ ) locations.

Histological findings of sinonasal bacteria balls

After we reviewed the pathologic slides from 247 cases of CRS including 40 cases of biomaterials (suspected fungal ball), 34 cases were reported as fungal ball which occurred in CRSsNP $(n=26)$ and CRSwNP $(n=8)$. When negative in GMS stain, we performed additional Gram stains and 6 cases were confirmed as bacterial balls. In H\&E stain, the matrix of bacterial balls was consisted of thick acellular materials (Fig. 3A, B). In Gram stain, the growth of purple-colored bacterial colonies were found but varied significantly from a few scattered form (Fig. 3C) to severe or crowded 
Table 2. Comparison of clinical characteristics between sinonasal fungal and bacterial balls in patients with chronic rhinosinusitis without nasal polyps

\begin{tabular}{lccc}
\hline Variable & Fungal ball & Bacterial ball & $P$-value \\
\hline No. & 26 & 4 & - \\
Sex (male:female) & $7: 19$ & $2: 2$ & 0.345 \\
Age (yr) & $63(58-67)$ & $57(54-60)$ & 0.123 \\
Atopy (\%) & 11.5 & 50 & 0.055 \\
Total IgE (IU/mL) & $45.5(16.1-56.0)$ & $65.5(43.6-92.6)$ & 0.273 \\
Peripheral eosinophils (\%) & $2.5(1.5-3.5)$ & $1.0(0.85-1.65)$ & 0.011 \\
CT score & $6(4-6)$ & $5(5-10.5)$ & 0.930 \\
Calcification in CT scan (\%) & 88.5 & 25 & 0.003 \\
\hline
\end{tabular}

Values are presented as median (interquartile range) unless otherwise indicated.

IgE, immunoglobulin E; CT, computed tomography.

form (Fig. 3D). Bacterial colonies were found in both central and peripheral portions of biomatrix. In addition, various amounts of inflammatory cells were infiltrated near bacterial colonies and they were mostly consisted of neutrophils and lymphocytes.

\section{Comparison of clinical characteristics between fungal and bacterial balls}

Fungal and bacterial balls are all common in patients with CRSsNP and have propensity to involve the maxillary sinus. In addition, it is difficult to distinguish only by gross finding at the time of surgery. Therefore, understanding the differences from fungal ball will be helpful for diagnosis and treatment of bacterial ball. There were no significant differences in sex, age, atopy, total immunoglobulin $\mathrm{E}(\mathrm{IgE})$, and $\mathrm{CT}$ scores between two groups (Table 2). However, sinonasal bacterial ball showed significantly less peripheral eosinophils $(P=0.011)$ and calcification in $\mathrm{CT}$ scans $(P=0.003)$ than fungus ball. We summarize the above results on Table 3.

\section{DISCUSSION}

CRS has been known as multifactorial and heterogeneous disease with unclear etiology and pathogenesis. To date, there have been many studies on the pathogenesis of CRS including histopathology, inflammatory cells, $\mathrm{T}$ cell immune responses, tissue remodeling, epithelial barrier, and microorganisms $[1,6,7,12]$. In bacterial hypothesis of CRS, many factors such as superantigens, biofilm, and dysbiosis are involved [13-16]. Thus, bacteria will have a variety of behavioral patterns and survival strategies in vivo. And bacteria are likely to have other mechanisms such as bioball not yet known.

Most bacteria are known to exist in the form of biofilm rather than planktonic form in vivo [13,17]. Bacterial biofilm is defined as a complex and organized community of bacteria embedded in a self-produced extracellular polymeric substance, and it was known to be detected in $20.9 \%$ to $100 \%$ of CRS. It
Table 3. Clinical characteristics for sinonasal bacterial balls

\begin{tabular}{ll}
\hline Factor & \multicolumn{1}{c}{ Result } \\
\hline $\begin{array}{l}\text { Clinical finding } \\
\text { Polyp }\end{array}$ & CRSsNP>CRSwNP \\
$\begin{array}{l}\text { Disease side } \\
\text { Involved sinus }\end{array}$ & Unilateral > bilateral \\
Imaging study & Maxillary $>$ ethmoid \\
Computed tomography & Without calcification > with calcification \\
Operative finding & \\
Color of bioball & Green or brown \\
Condition of material & Gel-like or semisolid \\
Relationship to mucosa & Tightly adherent to sinus mucosa \\
Pathology & \\
GMS stain & Negative \\
Gram stain & Bacterial colonies \\
H\&E stain & Mucoid materials with inflammatory cells \\
& infiltration \\
\hline
\end{tabular}

CRSsNP, chronic rhinosinusitis without nasal polyps; CRSwNP, chronic rhinosinusitis with nasal polyps; GMS, Gomori-methenamine-silver; H\&E, hematoxylin and eosin.

has been reported to be associated with high CT score, antibiotic resistance, and poor prognosis. Fungus also causes various pathologies such as simple ball, allergic reaction, and tissue invasiveness. Moreover, recent study described that bacterial and fungal biofilm coexisted on the sinus mucosa of patients with fungus ball, and bacterial biofilm was associated with more severe disease. Thus, biosystem of the paranasal sinuses is more complex than expected.

In this study, bacterial ball occurred in $2.4 \%$ of CRS patients who underwent FESS and it showed lower prevalence than fungal ball or bacterial biofilm. Fungal and bacterial balls are common in CRSsNP and looked very similar, and therefore, we compared two kinds of bioball occurred in CRSsNP. They occurred mainly in the unilateral maxillary sinus of CRSsNP patients. In both, peripheral eosinophils were within the normal range but significantly lower in bacterial ball. This means that bacterial ball is independent of the Th2 response. Moreover, CT scans showed a clear difference between them. Most of fungal ball was accompanied by calcification $(88.5 \%$ ), whereas it was not in bacterial ball $(25 \%)$. Nevertheless, it was impossible to discriminate between them at the time of surgery. Both were seen as amorphous semisolid materials with green or brown color (Fig. 2). Therefore, all suspected fungal balls should be referred for biopsy. Gram stain will be essential for the diagnosis of bacterial ball because it can be overlooked only by H\&E stain and GMS stain. All bacterial balls showed negative findings in GMS stain. So far, there has been no study of suspected fungal ball showing negative in GMS stain. This is a bacterial ball. The H\&E stain of bacterial ball showed a very thick matrix with infiltration of inflammatory cells which were mainly neutrophils, but not eosinophils. This phenomenon supports the fact that bacterial balls were made by bacteria. The number and location of bacterial colonies present 
in bacterial balls varied greatly as shown in Fig. 3.

Since it was first discovered in 2004 [18], numerous studies have confirmed that the biofilm is an important factor for severe inflammation and recurrence of CRS [13,18-23]. Biofilm is surgically removed with mucosa, but cannot be completely cleaned because it is an invisible structure. On the other hand, since bacterial ball is macroscopic, it can be completely removed by FESS as in the case of fungal ball. The difference from the fungal ball is that bacterial ball is mainly present within the maxillary sinus and it is tightly attached to the antral mucosa and is more difficult to remove. Therefore, additional procedures such as antral puncture are sometimes needed for its complete removal. In our limited experiences, the prognosis for bacterial ball is good and largely similar to fungal ball. As shown above, bacterial ball differs from biofilm in many ways.

We summarized clinical characteristics for bacterial ball (Table 3). In most cases, bacterial ball is found in patients with CRSsNP rather than CRSwNP. Bacterial ball is mainly located in the maxillary sinus of one side but is not accompanied with calcification on CT scans. Unlike biofilm, bacterial ball can be grossly observed and diagnosed with H\&E stain and Gram stain. Histology shows that bacterial ball consists of acellular mucoid matrix and bacterial colonies. Bacterial ball might appear to be a new strategy for bacteria to survive in the paranasal sinuses but when noticed, it can be surgically removed completely. In this way, bacterial ball may contribute to fill the missing puzzle of CRS pathogenesis that has not been fully explained.

Our study has some limitations. First, this study was a retrospective review of clinical data, and therefore, we couldn't reveal a causal relationship between bacteria and bioball. In other words, it is possible that bacteria may be parasitic as a bystander or passenger in a biomatrix rather than making bioballs. Second, because middle meatal culture was rarely performed in this study, information on bacteria was not provided. Third, bacterial ball seems to be the result of another survival strategy of bacteria, but there is no information on how bacteria make bacterial ball.

In conclusion, our current study described an unusual findings of paranasal sinus in CRS patients. We named it bacterial ball (or bioball) because it consisted with bacteria and appeared similar to fungal ball. It is reasonable to suspect bacterial ball if the fungal ball-like materials are not associated with calcification on CT scans. Diagnosis of bacterial ball is based on histological examination including Gram stain showing bacterial colonies. Further research is needed to establish bacterial ball as a new phenotype of CRS.

\section{CONFLICT OF INTEREST}

No potential conflict of interest relevant to this article was reported.

\section{ACKNOWLEDGMENTS}

The authors wish to acknowledge residents from Hanyang University Hospital for their assistance as study coordinators for the patients involved in this study.

\section{REFERENCES}

1. Fokkens WJ, Lund VJ, Mullol J, Bachert C, Alobid I, Baroody F, et al. EPOS 2012: European position paper on rhinosinusitis and nasal polyps 2012: a summary for otorhinolaryngologists. Rhinology. 2012 Mar;50(1):1-12.

2. Adams PF, Lucas JW, Barnes PM. Summary health statistics for the U.S. population: National Health Interview Survey, 2006. Vital Health Stat 10. 2008 Jan;(236):1-104.

3. Jarvis D, Newson R, Lotvall J, Hastan D, Tomassen P, Keil T, et al. Asthma in adults and its association with chronic rhinosinusitis: the GA2LEN survey in Europe. Allergy. 2012 Jan;67(1):91-8.

4. Kim DH, Han K, Kim SW. Effect of chronic rhinosinusitis with or without nasal polyp on quality of life in South Korea: 5th Korea National Health and Nutrition Examination Survey Korean. Clin Exp Otorhinolaryngol. 2016 Jun;9(2):150-6.

5. Brandsted R, Sindwani R. Impact of depression on disease-specific symptoms and quality of life in patients with chronic rhinosinusitis. Am J Rhinol. 2007 Jan-Feb;21(1):50-4.

6. Stevens WW, Lee RJ, Schleimer RP, Cohen NA. Chronic rhinosinusitis pathogenesis. J Allergy Clin Immunol. 2015 Dec;136(6):1442-53.

7. Hulse KE, Stevens WW,Tan BK, Schleimer RP. Pathogenesis of nasal polyposis. Clin Exp Allergy. 2015 Feb;45(2):328-46.

8. Kennedy JL, Borish L. Chronic rhinosinusitis and antibiotics: the good, the bad, and the ugly. Am J Rhinol Allergy. 2013 Nov-Dec;27 (6):467-72.

9. Bachert C, Hamilos DL. Are antibiotics useful for chronic rhinosinusitis? J Allergy Clin Immunol Pract. 2016 Jul-Aug;4(4):629-38.

10. Head K, Chong LY, Piromchai P, Hopkins C, Philpott C, Schilder $\mathrm{AG}$, et al. Systemic and topical antibiotics for chronic rhinosinusitis. Cochrane Database Syst Rev. 2016 Apr;4:CD011994.

11. Kim HD, Lee DW, Pyo JY, Oh YH, Cho SH. Bioballs causing asymptomatic or recurrent acute rhinosinusitis: two cases. J Rhinol. 2016 May;23(1):55-9.

12. Van Crombruggen K, Zhang N, Gevaert P, Tomassen P, Bachert C. Pathogenesis of chronic rhinosinusitis: inflammation. J Allergy Clin Immunol. 2011 Oct;128(4):728-32.

13. Kilty SJ, Desrosiers MY.The role of bacterial biofilms and the pathophysiology of chronic rhinosinusitis. Curr Allergy Asthma Rep. 2008 May;8(3):227-33.

14. Bernstein JM, Ballow M, Schlievert PM, Rich G, Allen C, Dryja D. A superantigen hypothesis for the pathogenesis of chronic hyperplastic sinusitis with massive nasal polyposis. Am J Rhinol. 2003 Nov-Dec; 17(6):321-6.

15. Schubert MS. A superantigen hypothesis for the pathogenesis of chronic hypertrophic rhinosinusitis, allergic fungal sinusitis, and related disorders. Ann Allergy Asthma Immunol. 2001 Sep;87(3):181-8.

16. Choi EB, Hong SW, Kim DK, Jeon SG, Kim KR, Cho SH, et al. Decreased diversity of nasal microbiota and their secreted extracellular vesicles in patients with chronic rhinosinusitis based on a metagenomic analysis. Allergy. 2014 Apr;69(4):517-26.

17. Al-Mutairi D, Kilty SJ. Bacterial biofilms and the pathophysiology of chronic rhinosinusitis. Curr Opin Allergy Clin Immunol. 2011 Feb;11(1):18-23.

18. Perloff JR, Palmer JN. Evidence of bacterial biofilms on frontal re- 
cess stents in patients with chronic rhinosinusitis. Am J Rhinol. 2004 Nov-Dec;18(6):377-80.

19. Prince AA, Steiger JD, Khalid AN, Dogrhamji L, Reger C, Eau Claire $\mathrm{S}$, et al. Prevalence of biofilm-forming bacteria in chronic rhinosinusitis. Am J Rhinol. 2008 May-Jun;22(3):239-45.

20. Foreman A, Jervis-Bardy J, Wormald PJ. Do biofilms contribute to the initiation and recalcitrance of chronic rhinosinusitis? Laryngoscope. 2011 May;121(5):1085-91.

21. Hekiert AM, Kofonow JM, Doghramji L, Kennedy DW, Chiu AG,
Palmer JN, et al. Biofilms correlate with TH1 inflammation in the sinonasal tissue of patients with chronic rhinosinusitis. Otolaryngol Head Neck Surg. 2009 Oct;141(4):448-53.

22. Sanclement JA, Webster P, Thomas J, Ramadan HH. Bacterial biofilms in surgical specimens of patients with chronic rhinosinusitis. Laryngoscope. 2005 Apr;115(4):578-82.

23. Foreman A, Singhal D, Psaltis AJ, Wormald PJ.Targeted imaging modality selection for bacterial biofilms in chronic rhinosinusitis. Laryngoscope. $2010 \mathrm{Feb} ; 120(2): 427-31$. 